\title{
Adolescência e trabalho: significados, dificuldades repercussöes na saúde
}

Cibele Almeida Torres ${ }^{1}$

Paulo Henrique Alexandre de Paula ${ }^{2}$ Adriana Gomes Nogueira Ferreira ${ }^{3}$ Patrícia Neyva da Costa Pinheiro ${ }^{4}$

TORRES, C.A. et al. Adolescence and work: meanings, difficulties and health repercussions. Interface - Comunic., Saude, Educ., v.14, n.35, p.839-50, out./dez. 2010.

Work experiences of working adolescents and their health repercussions were investigated. This study was developed in a school in Fortaleza, Ceará, in 2008, with ten working adolescents. It was an exploratory study with a qualitative approach, and the data gathering tools were a focus group and field diary. The data analysis was guided by content analysis. The legal and ethical issues were respected. Through developing the study, four categories emerged: characteristics of the adolescents who participated in the study; meanings of the work experiences for the adolescents; working adolescents and the difficulties faced in work situations; repercussions of work situations on the field of adolescents' health. It was perceived that there was a set of circumstances that led the adolescents to be surrounded by vulnerabilities. Thus, preparation for healthcare professionals to attend to this public is fundamental, in order to provide comprehensive care and health promotion for these adolescents.

Keywords: Adolescence. Work. Health.
Foram investigadas experiências de trabalho de adolescentes trabalhadores e as repercussões na saúde. A pesquisa foi desenvolvida em uma escola de Fortaleza, Ceará, em 2008, com dez adolescentes trabalhadores. O estudo foi exploratório, com abordagem qualitativa, tendo o grupo focal e o diário de campo como instrumentos de coleta de dados. A análise dos dados seguiu a análise de conteúdo. Foram respeitados os aspectos legais e éticos. Com o desenvolvimento do estudo, surgiram quatro categorias: características dos sujeitos participantes do estudo; significados das experiências de trabalho para os adolescentes; adolescentes trabalhadores e dificuldades enfrentadas nas situações de trabalho; repercussões da situação de trabalho no campo da saúde dos adolescentes.

Percebeu-se que há toda uma conjuntura que leva os adolescentes a serem cercados por vulnerabilidades, sendo fundamental a preparação dos profissionais de saúde para atender tal público, proporcionando uma atenção integral e promovendo a saúde desses adolescentes.

Palavras-chave: Adolescente. Trabalho. Saúde.
${ }^{1}$ Universidade Federal do Ceará (UFCE). Rua Alexandre Baraúna, 1115. Rodolfo Teófilo. Fortaleza, Ceará, Brasil. 60.430-160. cibeleat@yahoo.com.br




\section{Introdução}

A adolescência compreende uma das etapas do desenvolvimento humano caracterizada por intensas mudanças nos quesitos biológicos, psíquicos e sociais. Trata-se de uma etapa repleta de conflitos pessoais e interpessoais em que os adolescentes recebem influências do contexto cultural no qual estão inseridos (Saito, 2001).

A Organização Mundial de Saúde considera adolescente o indivíduo de ambos os sexos com idades entre 10 e 19 anos (OMS, 1995). Já no Estatuto da Criança e do Adolescente, a adolescência começa aos 12 anos e vai até os 18 anos incompletos (Brasil, 2007). Nesta fase, com as diversas transformações, o adolescente passa a incorporar novas construções sociais e comportamentais, adquirindo, consequentemente, direitos e deveres relacionados à identidade familiar, sexual e laboral, embasados nas normas e valores socioculturais vigentes. É também nesta fase que se percebe grande vulnerabilidade física, psicológica e social (Heidemann, 2006).

No caso de países em desenvolvimento, caracterizados pelo empobrecimento e pela acessibilidade ao mercado de trabalho precarizado, tem grande relevância a questão da exploração do trabalho infanto-juvenil. Baseando-se em dados internacionais, poder-se-ia estimar que pelo menos metade dos adolescentes trabalhadores desenvolva atividades definidas como perigosas (International Labour Organization - ILO, 2002). No Brasil, as mudanças ocorridas na organização do trabalho a partir de 1970 provocaram repercussões nas condições de vida e trabalho, destacando-se a situação do trabalho infanto-juvenil, que assume proporções dramáticas e preocupantes (Minayo-Gomez, Meirelles, 1997).

Até o inicio da década de 1980, a legislação brasileira não seguia as normativas internacionais acerca do direito de crianças e adolescentes (Antão de Carvalho et al., 2003). Somente com a redemocratização do país e com a Constituição de 1988, foi possível dar maior visibilidade às necessidades de crianças e adolescentes e protegê-las com respaldo jurídico (Antão de Carvalho et al., 2003).

A Emenda $n^{\circ} 20$, de 15 de dezembro de 1998, alterou o art. $7^{\circ}$ da Constituição Federal, estabelecendo em 16 anos a idade mínima de acesso ao trabalho, exceção feita apenas ao emprego em regime de aprendizagem, permitido a partir de 14 anos (Brasil, 1988b). Em 1990, as crianças e os adolescentes obtiveram novas conquistas, com o Estatuto da Criança e do Adolescente, que dispõe sobre a proteção integral à criança e ao adolescente e regula o direito à profissionalização e à proteção do trabalho (Brasil, 1990).

Em 12 de junho de 2008, foi assinado o decreto, no País, que regulamenta a convenção n ${ }^{\circ} 182 \mathrm{da}$ Organização Internacional do Trabalho (OIT), na qual se eleva a quantidade de atividades econômicas enquadradas na lista das piores formas de trabalho infantil, estando presentes, dentre outras: a exploração sexual, o tráfico de drogas e o trabalho doméstico (Brasil, 2009).

No tocante às políticas públicas de Saúde relacionadas à saúde do trabalhador infanto-juvenil, o Ministério da Saúde elaborou e implantou uma Política Nacional de Saúde para a Erradicação do Trabalho Infantil e Proteção do Trabalhador Adolescente, por meio da Área Técnica de Saúde do Trabalhador. Esta Política considera o papel do Sistema Único de Saúde (SUS) prioritário na atenção integral à saúde das crianças e adolescentes trabalhadores, apresentando, no âmbito da atenção básica, um papel fundamental na aplicação desta política, pela sua ampla distribuição no País e por atender a um grande número de indivíduos abaixo dos 18 anos (Brasil, 2005). É importante incluir, também, o papel dos profissionais de saúde envolvidos com a saúde ocupacional, para a construção de um conjunto de ações de atenção integral à saúde de crianças e adolescentes, em situação de trabalho, destinadas à promoção, à proteção, à recuperação e à reabilitação da saúde.

Os profissionais de saúde, que atuam, sobretudo, no ramo da saúde pública, têm também responsabilidades no campo da saúde do trabalhador, com ações de: promoção da saúde; proteção contra os riscos decorrentes das atividades laborais; recuperação de lesões, doenças ocupacionais ou não ocupacionais, e sua reabilitação. Tornam-se, pois, fundamentais para a promoção da saúde dos adolescentes em situação de trabalho (Brasil, 2005).

Assim, percebendo a problemática da exploração de trabalho envolvendo adolescentes e as repercussões geradas em suas vidas, surgiu a necessidade de se desenvolver este estudo, que tem 
como objetivo investigar as experiências de trabalho de adolescentes trabalhadores e as repercussões no campo da saúde.

\section{Conduta metodológica}

O estudo, cuja abordagem é qualitativa, enquadra-se no tipo exploratório, já que sua finalidade foi reunir informações em geral a respeito do tema a ser pesquisado e aproximar-se da natureza do objeto de interesse e de suas manifestações (Rodrigues, 2007). Foi realizado em uma escola pública de Ensino Fundamental e Médio de um bairro periférico de Fortaleza, Ceará, durante o mês de junho de 2008.

Os sujeitos do estudo consistiram em dez adolescentes, selecionados a partir da população de 450 estudantes matriculados na escola onde foi realizada a pesquisa. A seleção seguiu os critérios de inclusão: ser adolescente de 12 a 18 anos incompletos, ser matriculado na escola, ter alguma experiência de trabalho atualmente ou anteriormente, querer participar da pesquisa e ter a aprovação do responsável.

Realizaram-se visitas nas salas de aula de Ensino Fundamental e Médio da escola, verificando aqueles estudantes que atendiam a todos os critérios de inclusão, alcançando-se os dez participantes do estudo. Todos os adolescentes selecionados, coincidentemente, estudavam no período noturno da escola, já que trabalhavam no período diurno. A escolha do tamanho da amostra da pesquisa qualitativa, em geral, é decidida por critérios distintos dos da pesquisa quantitativa, variando: pela importância dos sujeitos para o esclarecimento do assunto em foco, a facilidade de se encontrarem as pessoas, o tempo dos indivíduos para as entrevistas, entre outros (Triviños, 1987).

Foram utilizados, como técnica de coleta de dados, o grupo focal e o diário de campo para a obtenção de dados de natureza qualitativa.

O grupo focal permite analisar, de forma eficiente e em curto tempo, problemas na perspectiva da população, examinando: suas percepções, conceitos, opiniões, expectativas, representações culturais, universo cultural e vocabular (Westphal, Bogus, Faria, 1996). Os grupos focais abordaram: as experiências de trabalho dos adolescentes, os significados do trabalho para os adolescentes, saúde ocupacional, situações de riscos no trabalho precoce e reflexões nos encontros.

Deu apoio ao estudo um diário de campo, que permitiu descrições, comentários, reflexões, ideias e questionamentos que surgiram no decorrer da pesquisa e dos grupos focais. Seu conteúdo foi organizado e desenvolvido durante o processo investigatório, alinhando-se junto à análise dos dados coletados nos grupos focais.

Para a análise dos dados do diário de campo e dos grupos focais, utilizou-se a análise de conteúdo de Bardin, uma técnica que analisa as comunicações, objetivando reconhecer indicadores que permitam a aquisição de conhecimentos relativos às condições de produção e recepção destas mensagens, por meio de procedimentos sistemáticos e objetivos de descrição do conteúdo das mensagens (Bardin, 1977).

Foram respeitados os aspectos legais e éticos que envolvem pesquisas com seres humanos, conforme a Resolução 196/96 do Conselho Nacional de Saúde (Brasil, 2002). A participação dos estudantes foi iniciada após assinatura do Termo de Consentimento Livre e Esclarecido, por eles e seus responsáveis. Ressalta-se, ainda, que o estudo foi submetido à apreciação do Comitê de Ética em Pesquisa, obtendo aprovação. Para garantir o sigilo e anonimato dos adolescentes participantes deste estudo, eles foram nomeados, de forma fictícia, com as palavras "menino" ou "menina", de acordo com o gênero, seguidas de um número para diferenciá-los.

\section{Resultados e discussão}

A partir da sistematização e análise dos dados coletados nos grupos focais e no diário de campo, foram identificadas quatro categorias relevantes ao objeto de estudo: Características dos sujeitos participantes do estudo; Significados das experiências de trabalho para os adolescentes; Adolescentes 
trabalhadores e as dificuldades enfrentadas nas situações de trabalho; Repercussões da situação de trabalho no campo da saúde dos adolescentes.

Cada categoria temática emergiu do universo cultural dos participantes do estudo e apresentou relevância para o contexto dos adolescentes em situação de trabalho.

\section{Características dos sujeitos participantes do estudo}

Participaram do estudo dez adolescentes, sendo cinco mulheres e cinco homens, com 16 e 17 anos. Todos tinham experiência de trabalho, com sua iniciação antes dos 16 anos de idade, sendo que seis estavam trabalhando atualmente e quatro desempregados, porém buscando alguma atividade.

Dos adolescentes participantes, as situações de trabalho e experiências foram diversificadas: vendedoras de loja (um), de coco (um), serviços domésticos (dois), modelo (um), serviços gerais em revenda de carro (dois), serigrafista (um), auxiliar de escritório (um), e como ajudante do pai no mercadinho da família (um). Dentro destas atividades, nenhum dos dez adolescentes participantes do estudo tinha algum registro em Carteira de Trabalho e Previdência Social (CTPS), pelo empregador, ou recebia, pelo menos, um salário-mínimo, confirmando a precarização do trabalho a que são submetidos os adolescentes, para se inserirem no mercado de trabalho. Além disso, possuíam carga-horária elevada e desgastante, sem direitos trabalhistas relacionados a folgas, férias ou $13^{\circ}$ salário.

Neste sentido, estes dados são confirmados ao se saber que crianças e adolescentes de classes sociais desfavoráveis tendem a trabalhar elevado número de horas semanais e a receber baixos salários, poucos dispondo de cobertura previdenciária. Frequentemente, trabalham sem carteira assinada e são vítimas expressivas do subemprego, com dificuldades de acesso ao mercado de trabalho, devido: à destinação aos jovens das piores posições, elevada incidência de desemprego e emprego intermitente, más condições de trabalho, baixo grau de satisfação com as tarefas executadas, baixa remuneração e longa jornada (Gomes, 1990).

De posse dos dados levantados pela Pesquisa Nacional por Amostra de Domicílios de 2002, também se passou a ter uma nova configuração do fenômeno do trabalho infanto-juvenil no Brasil para a faixa etária de cinco a 15 anos. O universo dos trabalhadores infantis é majoritariamente masculino, ainda que, em algumas ocupações, como o trabalho infantil doméstico, haja predominância de mulheres. Do total de trabalhadores infantis, 49,8\% estão na zona rural e 50,2\% na urbana (IBGE, 2003).

Percebeu-se que a situação dos adolescentes participantes do estudo é confirmada pelas pesquisas brasileiras acerca da precarização do trabalho nesta faixa etária. Apesar dos esforços que foram realizados nos últimos 15 anos, ainda existem, no Brasil, mais de cinco milhões de crianças e adolescentes trabalhando em atividades proibidas pela legislação (IBGE, 2003).

Na busca de romper com esse quadro desfavorável, é fundamental a elaboração de ações intersetoriais, que alcancem a dimensão real do problema, incluindo o foco específico da saúde. Neste contexto problemático, que envolve estes adolescentes em situação de trabalho, o profissional de saúde - sobretudo o que atua na atenção primária - tem papel importante na identificação, acolhimento, caracterização desta realidade, intervenção intersetorial e notificação do problema, visando à promoção da dignidade humana.

\section{Significados das experiências de trabalho para os adolescentes}

De acordo com a análise dos dados, foi possível perceber que as experiências de trabalho são vivenciadas de formas diferenciadas pelos adolescentes. Alguns as veem como positivas para seu cotidiano, outros as consideram como experiências negativas, sendo estas realizadas de acordo com a necessidade.

Alguns adolescentes referem satisfação ao trabalharem para ter o recurso financeiro próprio e poderem adquirir certos bens de consumo que seus pais não poderiam prover: 


\begin{abstract}
"Eu trabalho pra poder gastar o dinheiro que eu suei pra conseguir, sabendo que fiz um esforço e não simplesmente minha mãe ou alguém que me deu. Dar aquele gosto que você realmente fez um esforço pra conseguir". (menina1)

"Eu trabalho pela necessidade de gastar, sou muito gastão, só gasto meu dinheiro com besteira. Ajudo minha mãe e o resto investi em besteira". (menino1)
\end{abstract}

Outros adolescentes prefeririam não trabalhar e poder passar aquele tempo dedicado aos estudos. Esse desejo está representado pela seguinte fala:

“Eu trabalho, mas preferiria estar estudando, porque é muita coisa pra gente trabalhar e estudar. É muito ruim. Eu não queria trabalhar agora não. Eu queria trabalhar quando terminasse os estudos, mas minha família não pode me mandar dinheiro. Depois de estudar eu iria trabalhar, pra não ter que depender". (menina3)

Um estudo realizado com adolescentes de São Paulo indicou que a representação do trabalho durante a adolescência, para os pesquisados, foi considerada positiva para a maioria dos adolescentes, reproduzindo um discurso moralista no qual o trabalho é responsável por dignificar o homem, mesmo que prejudique os estudos. Aponta também opiniões opostas, indicando que ou o trabalho acomoda os adolescentes, afastando-os dos estudos, ou traz um sentimento de mudança (Oliveira et al., 2005).

Outros adolescentes ainda referiram a importância de iniciarem o trabalho mais cedo, pela experiência, e já aprenderem um ofício, facilitando conseguirem empregos futuros, como representado pela fala a seguir:

"É bom que você começa a aprender logo, mais cedo". (menino3)

As narrativas evidenciam a dimensão cultural na iniciação precoce ao trabalho. Esta precocidade laboral ocorre no País como em diversas nações, por diferentes motivos, dentre eles: a desigualdade social, a pobreza, a necessidade de complementar a renda familiar. Isto, porém, não é a única motivação das famílias para introduzirem seus filhos precocemente no mundo do trabalho, havendo, atualmente, uma supervalorização cultural do trabalho também no âmbito moral, por acreditarem que o trabalho é a única forma de "libertar" os jovens da delinquência (Lima, 2008).

Com isso, valores culturais determinam uma aceitação social do trabalho precoce para as classes sociais desfavorecidas com a criação de mitos de que o trabalho evitará a permanência das crianças e adolescentes nas ruas, reduzindo o índice de delinquência infanto-juvenil, fazendo com que o trabalho seja aceito como a única e salvadora alternativa para redução daquela delinquência. Assim, a sociedade aceita o trabalho precoce independentemente da idade do trabalhador, dos ambientes de trabalho em que são inseridos, e não busca opções para a erradicação do trabalho precoce e para a criação de condições para a manutenção das crianças e adolescentes na escola.

Entender os motivos que levam o adolescente a trabalhar precocemente é importante para que o profissional de saúde que atende este indivíduo possa compreender seu entorno e implementar cuidados integrais e individualizados adequados à realidade e à necessidade dele. $O$ conhecimento acerca dos motivos que levam o adolescente a trabalhar precocemente também é relevante para que estes profissionais possam participar das ações inerentes à busca pela erradicação da exploração do trabalho infanto-juvenil.

\title{
As dificuldades enfrentadas pelos adolescentes nas situações de trabalho
}

Diversos são os problemas enfrentados pelos adolescentes em seus ambientes de trabalho, e conhecê-los é importante para que o profissional de saúde entenda suas consequências.

Os diálogos fomentados no grupo permitiram visualizar a complexa problemática que envolve o adolescente trabalhador. $O$ trabalho precarizado refletiu-se: nas queixas referentes às questões de 
remuneração, na carga-horária trabalhada, nas necessidades diárias ignoradas dos adolescentes, usurpando direitos inerentes ao trabalhador. O empregador, por outro lado, não promove suporte suficiente para os empregados, influenciando consideravelmente na saúde dos adolescentes:

"O patrão nunca paga o que é pra pagar". (menino3)

"O adolescente trabalha muito e ganha pouco. E a carga horária é maior do que era pra ser". (menina1)

"Eu trabalhava e eles não davam almoço e nem transporte. Eu ia de bicicleta e demorava quase 1 hora e meia". (menino1)

“Eu já trabalhei em um lugar que eu passava o dia todo em pé das 6:00 da manhã às 18:00. À noite não agüentava de tanta dor nas pernas". (menina2)

Ante tal problemática enfrentada pelo adolescente trabalhador, existem contradições entre a realidade e o aparato judicial acerca da sua condição. Sabe-se que, segundo a legislação brasileira, 16 anos é a idade mínima de acesso ao trabalho, proibindo-se qualquer emprego ou trabalho abaixo dos 16 anos, exceção feita apenas ao emprego em regime de aprendizagem, permitido a partir de 14 anos. Abaixo de 18 anos, o trabalho é proibido, sem exceção, quando é perigoso, insalubre, penoso, noturno e prejudicial ao desenvolvimento físico, psíquico, moral e social (Brasil, 1988a).

Além disso, sabe-se que as etapas de desenvolvimento e maturação, presentes na infância e adolescência, formam um complexo processo, que exige tempo, espaço e condições favoráveis para realizar sua transição em direção à vida adulta. Logo, a exaustão corporal provocada por uma sobrecarga de trabalho além do "suportável" pelo organismo do indivíduo, associada a um aporte nutricional insuficiente, parecem ser os fatores precipitantes para o desenvolvimento das patologias (Asmus, 2001).

Como os adolescentes participantes do estudo têm mais de 16 anos, todos estão com idade hábil para trabalhar, segundo a legislação brasileira, devendo, portanto, ter seus direitos trabalhistas e previdenciários seguidos, com atividades livres de insalubridade, periculosidade ou trabalho noturno. No entanto, acerca do (des)conhecimento quanto aos direitos trabalhistas, os diálogos dos grupos focais proporcionaram registros das seguintes falas dos adolescentes:

"O menor pode trabalhar a partir de quando ele agüentar". (menino1)

"O menor pode trabalhar se o patrão pagar um salário mínimo". (menino2)

"Menor não pode trabalhar, tem que estar no colégio". (menina1)

Percebe-se que eles desconhecem as leis que os amparam, expressando que todos podem trabalhar desde que consigam realizar a atividade ou o patrão pague um salário-mínimo. Outros já consideram que adolescentes menores de 18 anos não podem trabalhar, desconhecendo a faixa etária permitida ao trabalho e, mesmo assim, desrespeitando esta suposta afirmação, já que todos trabalham.

Durante o desenvolvimento da pesquisa, os participantes identificam-se, nas falas, como "menores", refletindo o termo usado, a partir do final do século XIX, no vocabulário jurídico brasileiro, que indicava, além da condição jurídica da criança e do adolescente, a sua condição de desamparo e abandono, judicializando a infância e criminalizando a pobreza. Esta legislação menorista lidava com crianças pobres e marginalizadas, tratando-as como simples objetos de tutela do Estado. Neste sentido, pela carga discriminatória, o termo "menor" passa a ser substituído pelos termos criança e adolescente, caracterizando um tratamento individualizado de respeito à dignidade humana e de sujeito de direitos (Scheinvar, 2002). Essa percepção do "menor" reflete um sentimento social na forma de visualizar e tratar o adolescente, inclusive no meio do trabalho, muitas vezes colocando o empregador como um tutor do adolescente trabalhador pobre e salvando-o da marginalização. 
Entende-se que a iniciação da atividade laboral na adolescência torna-se mais abrangente e subjetiva do que a legislação que estipula a faixa etária permitida para o trabalho. O ECA foi criado com o intuito de suprimir lacunas e tratar as crianças e adolescentes como singulares e sujeitos de direitos. Aplicado ao trabalho, o ECA busca uma mudança política no sentido da valorização da vida e transformação cultural, protegendo o adolescente da exploração pelo trabalho e das vulnerabilidades relacionadas.

Sabe-se, no entanto, que crianças e adolescentes com menos de 14 anos não podem exercer nenhuma atividade laboral, pela exposição aos riscos que as cargas físicas, psíquicas e sociais do trabalho geram, afetando o desenvolvimento das potencialidades culturais, emocionais e biológicas. Para os adolescentes maiores de 14 anos, torna-se necessária uma orientação para o desenvolvimento das atividades, prevenindo potenciais riscos à saúde e garantindo um aprendizado técnico-profissional. É primordial, então, para a preservação da saúde dos trabalhadores juvenis, que haja: sensibilização e capacitação de professores de educação; sensibilização e capacitação de profissionais da saúde; crescimento da articulação com os centros comunitários das comunidades e organizações não governamentais, e realização de pesquisas de investigação do nexo causal envolvendo a adolescência (Asmus et al., 2005).

A falta de uma posição ético-política na cultura trabalhista, identificando crianças e adolescentes como sujeitos de direitos, prejudica a efetivação do respeito ao desenvolvimento e dignidade dos jovens cidadãos. É necessária mudança cultural.

Sobre as leis existentes acerca do trabalhador, alguns dos adolescentes revelam que estas são empecilhos para seus anseios:

"Muitas vezes a lei atrapalha, por acabar dando menos oportunidade pra o adolescente que está precisando". (menino3)

“É melhor que a empresa não siga as leis de trabalho, pague menos de um salário mínimo pros adolescentes, porque dá mais oportunidade". (menina1)

Considerando os direitos assegurados nas legislações trabalhistas e de saúde, pode-se acrescentar que os direitos dos adolescentes devam ser respeitados para que estes não compreendam seu bemestar como algo prejudicial ao seu cotidiano enquanto trabalhador, e sim como algo que faz parte de sua dignidade. Os direitos à saúde, especificamente, precisam ser debatidos na sociedade, para que não se restrinjam a uma conquista por meio de ações institucionais organizadas e externalizadas, nem como um bem disponibilizado e adquirido por meio de processos mercantis ou políticos, nem como valor humanístico decorrente de atos solidários (Verdi, Coelho, 2005). Será necessário, assim, planejamento de políticas e concretização de programas e serviços de saúde capazes de gerar bem-estar e de evitar riscos, tanto para os sujeitos quanto para os grupos sociais.

Os adolescentes da pesquisa equivocaram-se quanto às leis trabalhistas, considerando-as, muitas vezes, como barreiras a sua admissão nas propostas de trabalho, indicando que as empresas não deveriam seguir as leis. Estas são questões que explicitam a percepção dos adolescentes ao identificarem os direitos como culturalmente estabelecidos, ao invés de naturalizá-los. Estes fatores os tornam vulneráveis a diversas situações negativas relacionadas às condições sociais e de saúde, necessitando-se sensibilidade para se perceberem as vulnerabilidades que expõem aquele adolescente a riscos e a melhor forma de intervir, buscando sempre a qualidade de vida e autoestima juvenil.

\section{Repercussões da situação de trabalho no campo da saúde dos adolescentes}

O ambiente de trabalho tem impacto significativo dentro do campo da saúde e da promoção da saúde de indivíduos, família e comunidade. Segundo a Carta de Ottawa, que direciona as bases da promoção da saúde, o trabalho deveria ser fonte de saúde para as pessoas, bem como a organização social do trabalho deveria contribuir para a constituição de uma sociedade mais saudável (Brasil, 2001).

As situações de trabalho descritas anteriormente revelam que, mesmo os adolescentes tendo percepção dos problemas de saúde presentes em sua realidade, não conseguem se autocuidar adequadamente devido à ameaça de perderem seus empregos: 
"No trabalho, se a gente tiver algum problema de saúde eles descontam o dia que faltei". (menino2)

"Quando eu trabalhava no "beco da poeira", eu chegava na minha casa e não conseguia nem andar com os pés inchados, não tinha tempo de ir no médico, não tinha tempo de fazer nada, ou eu trabalharia ou se eu fosse no médico teria que sair e se eu saísse iriam precisar de alguém e certamente pegaria meu lugar. Entendeu? Ai eu não queria deixar de trabalhar". (menina1)

Percebe-se a fragilidade dos vínculos empregatícios no relato da menina 1, que identifica o "Beco da Poeira" como uma exemplo de trabalho precarizado. O Centro Comercial de Pequenos Negócios de Vendedores Ambulantes (CPNVA), popularmente conhecido como "Beco da Poeira", localiza-se no centro comercial de Fortaleza desde 1991. Conforme o Portal de Serviços e Informações do Governo do Estado do Ceará (2004), no CPNVA, 85\% dos estabelecimentos comerciais são informais, não apresentando registro perante a junta comercial de Fortaleza.

Segundo Forte (2004), o CPNVA emprega, diretamente e indiretamente, mais de trinta mil pessoas. Abrange dois mil e trinta boxes, com, aproximadamente, $1,5 \mathrm{~m}^{2}$, sem conforto ou higiene adequada. Sua estrutura arquitetônica é precária, antiga e sem acabamento, com risco evidente de acidentes. Os produtos comercializados incluem, sobretudo: vestuário, calçados e acessórios - e, historicamente, praticam preços populares. As relações trabalhistas também são informais, não existindo vínculos empregatícios legalizados, caracterizando-se, eminentemente, por "contratos" temporários.

Consequentemente, o estabelecimento sendo informal, sem vínculos empregatícios e sem pagamento de impostos, possui mercadorias com valores abaixo da concorrência e atrai clientes de baixo poder aquisitivo.

Neste contexto do Beco da Poeira e em outros em semelhantes condições, o adolescente é percebido como uma mão-de-obra barata, vulnerável, com um imenso contingente desempregado, com escassez de postos de trabalho e necessitando de experiência. Assim, a realidade precária desencoraja o exercício da cidadania juvenil, como ir ao médico, por exemplo.

Reflete-se, pois, a necessidade de se implementar a promoção da saúde, ante os empecilhos presentes na realidade destes adolescentes. Como falar em promoção da saúde em um ambiente de trabalho que só produz lacunas e torna os adolescentes ainda mais vulneráveis?

É importante a atuação do poder público para se viabilizarem melhorias nestas instâncias, minimizando o desrespeito aos direitos destes adolescentes.

Sobre essas questões que envolvem saúde e trabalho, é necessário também perceber o que estes adolescentes entendem sobre risco presente no trabalho:

"O trabalhador tem risco em cortar a mão". (menino1)

"O risco é prejudicial para a nossa saúde". (menina2)

"Quem trabalha com altura e quem trabalha com animais tem risco". (menina4)

Essa questão relativa a riscos no trabalho está ligada à insalubridade. Segundo a Norma Regulamentadora $n^{\circ} 15$, que relata sobre estas condições, insalubridade é toda situação que exponha o trabalhador a circunstâncias acima do nível de tolerância. Nesta norma regulamentadora, são descritos cada nível de intolerância e o respectivo risco a que está exposto o trabalhador (Atlas, 2008).

Sobre as espécies de risco presentes no trabalho, eles fizeram uma diferenciação, apontando conhecimentos e experiência com esse tipo de atividade:

"Quem mexe com produtos de limpeza, às vezes fica com falta de ar". (menina2)

"Quem lida com risco biológico corre o risco de pegar doenças dos outros, no hospital". (menina1) 
"Risco ergonômico tem quem estuda e chega em casa toda doída". (menino3)

"Risco físico tem quem trabalha no frigorífico". (menino1)

Acerca da prevenção desses riscos, os adolescentes apontaram a necessidade do uso de equipamentos de proteção individual (EPI):

"Deve usar luva, máscara, bata, aqueles óculos pra prevenir os riscos". (menina3)

"Melhor usar os equipamentos do que não usar". (menina1)

"Caso a pessoa não usar, ela prejudicará ela mesmo, ela tem que ter consciência". (menina2).

Segundo a Norma Regulamentadora ${ }^{\circ}$ 06, EPI trata-se de todo dispositivo ou produto de uso individual utilizado pelo trabalhador, destinado à proteção de riscos suscetíveis de ameaçar a segurança e a saúde no trabalho. Deve ser distribuído gratuitamente, pelo empregador, ao empregado, bem como se deve orientar sobre a importância de seu uso. O trabalhador orientado tem por obrigação usar o EPI (Atlas, 2008).

A maioria dos adolescentes trabalhadores mencionou a importância de usarem os EPI, porém, um adolescente que está exposto a alguns riscos no trabalho não apresenta experiência positiva, revelando certa resistência em usá-los e a falta de orientação do empregador quanto ao seu uso:

"Nós que trabalhamos lavando carro, usamos muito produto químico, óleo. Aí tem a

máscara e o protetor do ouvido, mas incomoda muito, então não uso". (menino1).

Logo, as normas regulamentadoras devem ser obedecidas, sob risco de punição, visando sempre à saúde do trabalhador. A presença do risco é constante na vida dos adolescentes trabalhadores, porém, reagem de forma a naturalizá-los em seus cotidianos:

“Na serigrafia tem produto químico, mas a gente usa máscara direto. Também sinto um pouco de dor nas costas, mas chego em casa, deito, me estico, num instante passa a dor. Isso não é problema pra mim. Isso tudo é frescura". (menino2)

Nota-se, então, que o adolescente trabalhador se encontra em situações de vulnerabilidade particulares no campo da saúde, influenciadas por: medos e inseguranças de perder o emprego, independência financeira, riscos no trabalho, uso de EPI, dentre outros.

Além dos fatores inerentes ao trabalho que podem influenciar na saúde destes adolescentes, eles ainda reveleram a independência financeira como algo que deve ser investigado para se entender se isto torna os adolescentes mais vulneráveis:

“Depende da pessoa. Se ele tiver dinheiro, acha que pode sair com um monte de mulher é arriscado, ele pode pegar alguma DST". (menino1)

"Ele pode correr o risco de se ficar muito bêbado, pegar qualquer uma por ai e ficar doente". (menina2)

Nas falas, revelaram-se relações entre a obtenção de recursos financeiros pelo adolescente e sua exposição a vulnerabilidades sociais e de saúde. Nos exemplos relatados, identificaram-se as doenças sexualmente transmissíveis (DST) como ponto a ser analisado. Entendendo que, dentre as áreas de possível consumo dos adolescentes, encontram-se as festas e ingestão de bebidas alcoólicas, os participantes do estudo relacionaram esta situação à vulnerabilidade às DST. 
No contexto atual de globalização e cultura pop, o século XXI remonta ao consumismo com que a sociedade se escraviza atualmente, incluindo os adolescentes e jovens, adentrando no mercado de trabalho. Este jovem, abduzido pelo consumo, inicia-se no processo de endividamento e busca urgente por fonte de renda, sendo assim público fácil para ingressar no mercado de trabalho informal e temporário. Este desenrolar de acontecimentos enquadra o adolescente numa situação de trabalho precário e difícil discernimento para o consumo controlado. Neste aspecto, a situação é inconsolável, pela ineficácia da escola em viabilizar novas realidades frente às relações de trabalho e emprego precarizadas. Porém, a esperança renasce perante o impulso dos jovens na criatividade por ideais sonhados ou na batalha pela própria sobrevivência (Pais, 2001).

\section{Considerações finais}

Com o desenvolvimento deste estudo e o auxílio da revisão de literatura nas temáticas pertinentes, foi possível expandir a visualização destas adolescências no mundo do trabalho. Há toda uma conjuntura que leva os adolescentes a serem cercados por vulnerabilidades, alegrias, medos, perigos, contradições e singularidades nas situações de trabalho, e isto é percebido no desenvolvimento das categorias temáticas deste estudo. O grupo focal proporcionou um desvelamento destas crenças e valores, contribuindo para o entendimento do ser adolescente e o trabalho.

O estudo teve relevância por evidenciar reflexões direcionadas à saúde dos adolescentes trabalhadores e as repercussões na proteção e promoção da saúde destes indivíduos, contribuindo para atuação dos profissionais de saúde neste âmbito. Percebeu-se a complexidade da questão do trabalho na adolescência, além de, muitas vezes, sua crueldade e magnitude devido a fatores conjunturais que tornam estes grupos vulneráveis. Os adolescentes e jovens, dentre outros agrupamentos sociais vulneráveis, representam, nas relações entre trabalho e capital da sociedade atual de ideário liberal, os de menor poder na negociação com o capital, sendo explorados. A reversão deste quadro implicaria a produção de uma cultura de direitos, repercutindo nas relações trabalhistas.

Pensa-se que, pelos significados das experiências de trabalho, pelas suas dificuldades e pelas repercussões da situação de trabalho no campo da saúde dos adolescentes, é fundamental que os profissionais de saúde estejam preparados para atender tal público, proporcionando uma atenção integral e promovendo a saúde destes trabalhadores.

Na perspectiva da promoção da saúde dos adolescentes trabalhadores, a saúde coletiva tem prioritária atenção na ressignificação das suas ações, revendo suas limitações e ações reducionistas e, assim, articulando inovações que percebam os adolescentes com suas particularidades e necessidades. Assim, as políticas públicas para os adolescentes trabalhadores devem ser formuladas com suporte em novas tendências de práticas de saúde, priorizando a intersetorialidade, para a efetivação do ser adolescente saudável, com qualidade de vida e satisfeito com a atenção a sua saúde.

Portanto, há necessidade de desenvolvimento de estudos - tanto de pesquisa como de extensão que esclareçam as particularidades dos adolescentes nas atividades de trabalho, bem como estimulem ações que possam transformar as atitudes dos espaços coletivos que cercam estes adolescentes.

\section{Colaboradores}

Os autores trabalharam juntos em todas as etapas de produção do manuscrito. 


\section{Referências}

ANTÃO DE CARVALHO, H.J. et al. Análise e recomendações para a melhor regulamentação e cumprimento da normativa nacional e internacional sobre o trabalho de crianças e adolescentes no Brasil. Brasília: OIT / Programa IPEC Sudamérica, 2003.

ASMUS, C.I.F. Avaliação do processo produtivo em mineração de diamantes e suas repercussões sobre a saúde dos adolescentes garimpeiros. 2001. Tese (Doutorado) Coordenação dos Programas de Pós-graduação em Engenharia, Universidade Federal do Rio de Janeiro, Rio de Janeiro. 2001.

ASMUS, C.I.R.F. et al. Atenção integral à saúde de adolescentes em situação de trabalho: lições aprendidas. Cienc. Saude Colet., v.10, n.4, p.953-60, 2005.

ATLAS. Manuais de legislação. Segurança e medicina do trabalho. 62.ed. São Paulo: Atlas, 2008

BARDIN, L. Análise de conteúdo. Lisboa: Edições 70, 1977.

BRASIL. Decreto n.6.481, de 12 de junho de 2008. Regulamenta os artigos $3^{\circ}$, alínea "d", e $4^{\circ}$ da Convenção 182 da Organização Internacional do Trabalho (OIT) que trata da proibição das piores formas de trabalho infantil. Disponível em: <http:// www.planalto.gov.br/ccivil_03/_Ato2007-2010/2008/Decreto/D6481.htm >. Acesso em: 01 dez. 2009.

Ministério da Saúde. Estatuto da Criança e do Adolescente. 3. ed. Brasília: Editora do Ministério da Saúde, 2007.

Ministério da Saúde. Trabalho infantil: diretrizes para atenção integral à saúde de crianças e adolescentes economicamente ativos. Brasília: MS, 2005.

Ministério da Saúde. Manual operacional para comitês de ética em pesquisa. Brasília: MS, 2002. MS, 2001

Ministério da Saúde. Promoção da saúde: Carta de Ottawa (1986). Brasília:

Constituição da República Federativa do Brasil. Brasília: Senado, 1988a.

Emenda Constitucional n.20, de 8 de dezembro de 1998. Dá nova redação ao $\overline{\text { art. } 7^{\circ}}$ da Constituição Federal, alterando e inserindo parágrafo. Lex-coletânea de legislação e jurisprudência: legislação federal e marginalia. Brasília, 1998 b.

CEARÁ. Portal de Serviços e Informações do Governo do Estado do Ceará. Governo estimula comerciantes do Beco da Poeira a saírem da informalidade. 2004. Disponível em: <http://www25.ceara.gov.br/noticias/noticias_detalhes.asp?nCodigoNoticia $=11962>$. Acesso em: 13 set. 2009 .

FORTE, L. Beco da Poeira atrai compradores do N/ NE. Disponível em: < http:// www.geranegocio.com.br/html/geral/vermateria. asp? $\mathrm{id}=13359 \&$ area $=4 \&$ titulo $=$ Beco $\%$ 20da\% 20Poeira\% 20atrai\% 20compradores \% 20do\% 20N/NE\&parte $=1>$. Acesso em: 13 set. 2009.

GOMES, C. A. O jovem e o desafio do trabalho. São Paulo: EPU, 1990.

HEIDEMANN, M. Adolescência e saúde: uma visão preventiva: para profissionais de saúde e educação. Petrópolis: Vozes, 2006.

IBGE. Pesquisa Nacional por Amostra de Domicílios - 2002: microdados. Rio de Janeiro: IBGE, 2003.

INTERNATIONAL LABOUR ORGANIZATION - ILO. Every child counts: new global estimates on child labour. Geneva, 2002. 
LIMA, C.G.C. Trabalho precoce, saúde e desenvolvimento mental. In: RIBEIRO FILHO, A.C. et al. (Orgs.). O impacto do trabalho precoce na vida de crianças e adolescentes: aspectos da saúde física e mental, cultural e econômico. Disponível em: <http:// www.mte.gov.br/trab_infantil/pub_541.pdf>. Acesso em: 29 jul. 2008.

MINAYO-GOMEZ, C.; MEIRELLES, Z.V. Crianças e adolescentes trabalhadores: um compromisso para a saúde coletiva. Cad. Saude Publica, v.13, supl.2, p.135-40, 1997.

OLIVEIRA, D.C. et al. A positividade e a negatividade do trabalho nas representações sociais de adolescentes. Psicol. Reflex. Crit., v.18, n.1, p.125-33, 2005.

ORGANIZAÇÃO MUNDIAL DE SAÚDE - OMS. La salud de los jóvenes: un reto y una esperanza. Geneva: OMS, 1995.

PAIS, J.M. Ganchos, tachos e biscates: jovens, trabalho e futuro. Porto: Ambar, 2001.

RODRIGUES, R.M. Pesquisa acadêmica: como facilitar o processo de preparação de suas etapas. São Paulo: Atlas, 2007.

SAITO, M.I. Adolescência e projeto de vida: o adolescente como protagonista e agente de transformação - a prevenção em questão. In: SAITO, M.I.; SILVA, L.E.V. (Orgs.).

Adolescência: prevenção e risco. São Paulo: Atheneu, 2001. p.559-65.

SCHEINVAR, E. Idade e proteção: fundamentos legais para a criminalização da criança, do adolescente e da família (pobres). In: NASCIMENTO, M.L. (Orgs.). Pivetes: a produção de infâncias desiguais. Niterói: Intertexto e Oficina do autor, 2002. p.89-109.

TRIVIÑOS, A.N.S. Introdução à pesquisa em ciências sociais: a pesquisa qualitativa em educação. São Paulo: Atlas, 1987.

VERDI, M.; COELHO, E.B.S. Do Higienismo ao SUS: a evolução das políticas de saúde no Brasil. In: VERDI, M.; BOEHS, A.E; ZAMPIERI, M.F.M. (Orgs.). Enfermagem na Atenção Primária de Saúde: textos fundamentais. Florianópolis: UFSC/ NFR/ SBP, 2005. p.17-59.

WESTPHAL, M.F.; BOGUS, C.M.; FARIA, M.M. Grupos focais: experiências precursoras em programas educativos em saúde no Brasil. Bol. Of. Sanit. Panam., v.120, n.6, p.472-81, 1996.

TORRES, C.A. et al. Adolescencia y trabajo: significados, dificultades y repercusiones en la salud. Interface - Comunic., Saude, Educ., v.14, n.35, p.839-50, out./dez. 2010.

Se han investigado experiencias de trabajo de adolescentes trabajadores y las repercusiones en la salud. La investigación se ha desarrollado en una escuela de Fortaleza, estado de Ceará, Brasil, en 2008, con diez adolescentes trabajadores. El estudio ha sido exploratorio con planteamiento cualitativo, con el grupo focal y el diario de campo como instrumentos de colecta de datos. El análisis de los datos sigue el análisis de contenido. Se respetan los aspectos legales y éticos. En el desarrollo del estudio surgen cuatro categorías: características de los sujetos participantes del estudio; significados de las experiencias de trabajo para los adolescentes; adolescentes trabajadores y dificultades afrontadas en las situaciones de trabajo; repercusiones de la situación de trabajo en el campo de la salud de los adolescentes. Nótase que hay toda una coyuntura que lleva a los adolescentes a un cerco de vulnerabilidades, por lo que resulta fundamental la preparación de los profesionales de salud para atender tal público, proporcionando una atención íntegra y promoviendo la salud de estos adolescentes.

Palabras clave: Adolescente. Trabajo. Salud. 